\title{
UNA DIATRIBA HISTORIOGRÁFICA EN TORNO AL PADRE LUIS DE VALDIVIA, S.I. (1876-1914) ${ }^{1}$
}

\author{
José Manuel DÍAZ BLANCO \\ Universidad de Sevilla
}

\begin{abstract}
RESUMEN: Este trabajo analiza los documentos que posee el Archivo del Colegio de San Ignacio de Santiago de Chile sobre la polémica que enfrentó a Crescente Errázuriz con los padres Zoilo Villalón, S.I., y Pablo Hernández, S.I., acerca de Luis de Valdivia y la Guerra Defensiva. En esta polémica, Errázuriz venció a los historiadores jesuitas y creó una nueva imagen de Valdivia, que contrastaba con las representaciones anteriores de la época colonial.

PALABRAS CLAVE: Luis de Valdivia, Guerra Defensiva, historia, Crescente Errázuriz, Zoilo Villalón, Pablo Hernández.

ABSTRACT: This paper analyzes documents from the Archive of Colegio de San Ignacio of Santiago de Chile from the debate between Crescente Errázuriz and Fathers Zoilo Villalón, S.J., and Pablo Hernández, S.J., regarding Luis de Valdivia and the Defensive War. In this polemic Errázuriz defeated the Jesuit historians and created a new image of Valdivia that differed from earlier representations from the colonial era.
\end{abstract}

KEYWORDS: Luis de Valdivia, Defensive War, History, Crescente Errázuriz, Zoilo Villalón, Pablo Hernández.

El P. Luis de Valdivia y su Guerra Defensiva (1612-1626) se vieron siempre envueltos en la polémica. Partidarios y detractores de aquella política se enfrentaron durante los años en que se encontró vigente y las crónicas coloniales continuaron su gresca, retomando los argumentos a favor y en contra de unos y otros. Los cronistas militares la despreciaron tanto como los soldados que la repugnaron cuando se hallaba en pie $^{2}$ y los cronistas jesuitas la glorificaron tan

${ }^{1}$ Recibido el 15 de julio y aceptado para su publicación el 22 de septiembre de 2009.

2 Tesillo, S. (1864 [1647]). Guerra de Chile, causas de su duración y medios para su fin. Santiago: Imprenta del Ferrocarril; QuiRogA, J. de (1979). Memorias de los sucesos de la guerra de Chile, Santiago: Imprenta del Ferrocarril; CARvallo Goyeneche, V. (1875). Descripción históricojeográfica del Reino de Chile. Santiago: Imprenta de la Librería del Mercurio. 
desmesuradamente como los partidarios de Valdivia cuando éste se encontraba aún en Chile ${ }^{3}$. En este duelo, las crónicas jesuitas, escritas por individuos más cultivados y con acceso a mejores fuentes de información, resultaron vencedoras, pero no de forma definitiva, porque después de la Independencia las plumas siguieron desenvainadas.

Para los historiadores chilenos de finales del siglo XIX y comienzos del XX, que vivieron la Pacificación de la Araucanía, Valdivia y la Guerra Defensiva no habitaban en los anaqueles polvorientos de la Historia, sino entre los intrincados entresijos de la vida y la actualidad política. Los mejores deseos del Positivismo triunfante en el mundo académico no pudieron ayudarlos a aislar su obra del influjo de estas circunstancias y a pesar de que se rescataron numerosos documentos del olvido absoluto en que yacían en el Archivo General de Indias (que nadie había consultado desde el siglo XVII), nada de ello sirvió para que los nuevos trabajos históricos superasen en imparcialidad a las antiguas crónicas.

Ejemplo de todo esto fue la trayectoria de don Crescente Errázuriz, uno de esos grandes historiadores del Chile de entonces ${ }^{4}$, que se enfrentó dos veces con la Compañía de Jesús a causa de sus escritos sobre el padre Valdivia, de explícito perfil desmitificador y crítico, primero frente al P. Zoilo Villalón y después contra el P. Pablo Hernández. Este trabajo no pretende realizar un análisis completo de esta guerra de dos batallas. Algo así requeriría un repaso íntegro a todos los libros y artículos que los tres principales implicados publicaron sobre el tema, operación tediosa, que requiere más espacio del que es razonable ocupar aquí y que nos adentraría en pormenores desfasados que hoy ya carecen completamente de interés.

${ }^{3}$ Rivadeneira, P. de y Alegambe, P. (1643). Bibliotheca Scriptorum Societatis Iesu, Amberes; Nieremberg, J. E. (1645). Honor del Gran Patriarca San Ignacio de Loyola, fundador de la Compañia de Iesus, en que se proponen su vida, y la de su Discipulo el apostol de las Indias $S$. Francisco Xavier con la milagrosa Historia del admirable Padre Marcelo Mastrilli, y las noticias de gran multitud de Hijos del mismo S. Ignacio; varones clarissimos en santidad, dotrina, trabajos, y obras maravillosas en seruicio de la Iglesia, Madrid; Ovalle, A. DE (2003 [1646]). Histórica relación del reino de Chile, Santiago: Pehuén; Rosales, D. de (1877). Historia general del reino de Chile, Flandes indiano, Valparaíso: Imprenta del Mercurio; TECHO, N. DEL (1897 [1673]). Historia de la provincia del Paraguay de la Compañia de Jesús. Madrid-Asunción; OlIVARES, M. DE (1864). Historia militar, civil y sagrada de Chile. Santiago: Imprenta del Ferrocarril; LozANO, P. (1970). Historia de la Compañia de Jesús en la provincia de Paraguay. Westmead: Gregg International Publishers Limited.

${ }^{4}$ Hay una semblanza sobre él en los varios artículos que conforman el homenaje que se le rindió en Revista Chilena de Historia y Geografia, 76 (1932). Sin embargo, nada mejor para conocerlo que sus propias memorias: ERrÁzuriz, C. (1934). Algo de lo que he visto. Memorias de don Crescente Errázuriz, Nascimento, Santiago, 
En vez de eso, nos proponemos ahora un objetivo más limitado: dar a conocer la documentación que de esta polémica historiográfica conserva desde hace décadas el Archivo del Colegio de San Ignacio de Santiago de Chile (ACSI), una institución modesta, pero modélica en la gestión del patrimonio que conserva ${ }^{5}$.

Desde que los propios protagonistas de este debate lo hicieran, el primer historiador que utilizó la documentación sobre la Guerra Defensiva de este centro jesuita fue el P. Eugene H. Körth, S.I., en su libro Spanish Policy in Colonial Chile. The struggle for social justice ${ }^{6}$, en el que cita repetidamente documentos de un volumen catalogado como ACSI, A-II-63. Una vez allí, puede comprobarse que dicho tomo -dos en realidad- no son ni más ni menos que las copias de documentos originales sobre la Guerra Defensiva que el P. Pablo Pastells, S.I. ${ }^{7}$, copió en el Archivo General de Indias y luego envió desde Sevilla a Santiago de Chile en 1908 para que Hernández compusiese su defensa del P. Valdivia frente a los improperios de Errázuriz. Más aun, puede percibirse que este debate, a causa de su doble tempo, generó dos conjuntos documentales de esta naturaleza:

1. ACSI, caja 2/J/294, carpeta 22: Archivo de Indias - Documentos sobre el P. Valdivia traídos (á lo que parece) hacia 1878, después de la polémica del P. Zoilo Villalón con D. Crescente Errázuriz.

2. ACSI, caja 2/J/295, carpeta $3^{8}$ : Documentos del Archivo General de Indias de Sevilla enviados por el P. Pablo Pastells, S.I., al colegio S.I. de San Ignacio en

5 Moreno Jeria, R. (2007). Misiones en Chile Austral: los jesuitas en Chiloé, 1608-1768. Sevilla: CSIC-Universidad de Sevilla-Diputación de Sevilla, actualiza la designación como Archivo de la Provincia Jesuita de la Provincia Jesuita de Chile (ASJCh). Se trata del mismo archivo.

${ }^{6}$ KÖRTH, E. H. (1968). Spanish Policy in Colonial Chile. The struggle for social justice. Stanford: Universidad.

${ }^{7}$ PASTELls fue un profundo conocedor de los fondos del Archivo de Indias, como demuestra su (1912-1959). Historia de la Compañía de Jesús en la provincia del Paraguay (Argentina, Paraguay, Uruguay, Perú, Bolivia y Brasil según los documentos originales del Archivo General de Indias). Madrid: CSIC. También su colaboración en (1925-1933). Catálogo de documentos relativos a las Islas Filipinas existentes en el Archivo de Indias de Sevilla, Barcelona: Co. Gral. De Tabacos de Filipinas. Dio buena cuenta de su pericia acompañando estos dos volúmenes de copias de los que aquí se habla con un documento: ACSI, caja 2/J/294, carp. 25, doc. 7; "Muestra del modo como se han interpretado algunos documentos en los capítulos manuscritos que tratan del P. Valdivia". En él, Pastells da su opinión personal sobre los que entiende errores de Errázuriz amparándose en "la circunstancia de haber empleado yo varios meses continuos ocupando seis horas diarias en registrar documentos del Archivo de Indias en Sevilla y haber examinado en ese tiempo decenas de Consultas [del Consejo de Indias]".

${ }^{8}$ Esta catalogación interna difiere de la empleada por Körth, a causa de una reordenación llevada a cabo por el P. Eugene Rooney, S.I., archivero actual del centro. Rooney es todo un ejemplo de buen 
Santiago de Chile, año 1908 con ocasión de un estudio histórico sobre el P. Luis de Valdivia (2 vols. $)^{9}$.

Por supuesto, para quien puede disponer de los originales del Archivo de Indias, el valor de estos volúmenes de copias es bastante relativo. Su encanto resulta indudable; todavía hoy provoca una honda emoción sumergirse en las páginas que cruzaron el océano Atlántico en el siglo XIX y a comienzos del siglo XX portando los sueños y desvelos de los historiadores chilenos de entonces: una documentación veraz sobre ese P. Valdivia que tanto los apasionaba. Sin embargo, si hablamos en términos de utilidad, los adjetivos tienen forzosamente que perder entusiasmo. Afortunadamente, los jesuitas no sólo dejaron en su archivo los repertorios de fuentes que habían reunido durante la polémica, sino también los documentos que ellos mismos habían generado al enzarzarse en ella: cartas, actas de reuniones, apuntes... Un material inédito en su mayor parte y precioso, fundamental para conocer desde dentro la última gran polémica que generase la Guerra Defensiva antes de que los estudios valdivianos se normalizasen durante la segunda mitad del siglo XX.

$$
* * *
$$

"La memoria del Padre Valdivia, gracias a las alabanzas de los cronistas y a la falta de conocimiento de los documentos de la época, pasaba por una de las más grandes e inmaculadas de la colonia". Desde los inicios de su trayectoria investigadora, Crescente Errázuriz, autor de estas palabras, estuvo convencido de la necesidad de desvanecer el espejismo que habían creado los cronistas jesuitas coloniales en torno a Valdivia. Sus estudios acerca de la implantación del Cristianismo en su país, plasmados en Los oríjenes de la Iglesia Chilena ${ }^{10}$, le aportaron "la convicción de que la conducta de Luis de Valdivia merecía en algunos puntos severos reproches" "11 y él intentó hacerlo en una serie de artículos

hacer archivístico y le agradezco enormemente la amabilidad y atención que me dispensó los días que trabajé allí.

${ }^{9}$ Al final del segundo volumen, en la página 949, se encuentra la certificación del que entonces era director del Archivo de Indias, don Pedro Torres Lanzas, de 4 de mayo de 1908. Según se explicita en ella, ambos tomos costaron a la Compañía 8 pesetas, a los que se sumó una peseta más por las copias de algunas cartas del conde de Castro y otros documentos que empleó Pablo Hernández para escribir su obrita de 1908.

${ }^{10}$ ERrÁzURIZ, C. (1873). Los oríjenes de la Iglesia chilena 1540-1603. Santiago: Imprenta del Correo.

${ }^{11}$ ERrÁzURIZ. Algo de lo que he visto, p. 210. Sin embargo, es de notar que, si efectivamente ocurrió así, Errázuriz silenció esas primeras dudas, porque en el citado libro de Los oríjenes de la Iglesia chilena se deshace en elogios hacia Valdivia siempre que habla de él. En la página 14 ya dice 
aparecidos en $1876^{12}$. Lógicamente, ninguna de esas publicaciones pasó desapercibida para la Compañía de Jesús, que entendió que debía salir en defensa de su antiguo miembro para proteger el honor del Instituto. Pueden suponerse con facilidad las razones corporativas que la obligaban a ello, si bien Errázuriz nunca dejó de pensar que los jesuitas actuaron creyendo que él había actuado de mala fe por motivos económicos ${ }^{13}$.

La documentación de esta primera parte de la polémica se conserva fundamentalmente en la carpeta 24 de la caja 2/J/294, que contiene la correspondencia de Villalón, una semblanza biográfica del P. Valdivia (debida a alguien que firmó con las iniciales J.J.A.), un repertorio de citas de autoridades recogidas por el P. Francisco Enrich, S.I. ${ }^{14}$, y una cronología con relación de fuentes disponibles. En total, más de una decena de documentos a los que debe añadirse la defensa de Valdivia que Villalón publicó fragmentadamente en el periódico El Estandarte Católico y que el archivo jesuita conserva íntegra en la caja 2/J/297, carp. 10, dentro de un volumen al que alguien tituló El P. Luis de Valdivia. Polémica ventilada entre el presbitero D. Crescente Errázuriz i el padre S. J. Zoilo Villalón entre febrero y mayo de 1877.

Según testimonio del P. Francisco Ginebra ${ }^{15}$, que fue consultor del Colegio de San Ignacio aquel año de 1877, la decisión de contraatacar partió del P. Baltasar

de él lo siguiente: "Al hablar de la libertad del indíjena i de sus constantes defensores, hai un nombre que la memoria de todos recuerda en el acto i que todos los labios pronuncian: Luis de Valdivia ha tenido el honor de hacer suya una causa heroica i cualquier hombre de sentimientos jenerosos, sean cuales fueren sus ideas i preocupaciones, se siente entre nosotros lleno de veneración ante esa gran figura". Luego desarrolla estas ideas de la Introducción en las pp. 431-437, que tratan el "Establecimiento en Chile de la Compañía de Jesus".

12 Todos bajo el título "El padre Luis de Valdivia en la Corte de España". Pueden consultarse todos en el Archivo Histórico de la Provincia de Toledo de la Compañía de Jesús, estante 2, caja 85, donde se hallan recortados y pegados uno detrás de otro en un solo volumen.

${ }^{13}$ ERRÁZURIZ. Algo de lo que he visto, p. 210: "cierta señora iba a hacer una donación importante a El Estandarte Católico, y uno de los padres de la Compañía la disuadió e hizo que diese esa suma a El Independiente. Creyéndome conocedor del incidente, atribuyeron mis escritos sobre Luis de Valdivia a venganza por aquella mala voluntad con nuestro diario y, sin más auto ni traslado, supusieron que mis asertos eran falsos y calumniosos, fruto de la pasión". No hay ningún testimonio jesuita sobre este particular.

${ }^{14}$ Como se sabe, es el autor de la famosa (1891). Historia de la Compañía de Jesús en Chile. Barcelona.

${ }^{15}$ Nació el 7 de junio de 1839 en Vich y murió el 26 de enero de 1907. Entró en la Compañía el 21 de agosto de 1859 y se ordenó el 15 de enero de 1871. Véase HANISCH EsPíndOLA, W. (1994). «El P. Francisco Ginebra, S. J., filósofo y pedagogo (1839-1907)». Anuario de Historia de la Iglesia en Chile, 12, pp. 79-98. 
Homs ${ }^{16}$. En efecto, por carta de 17 de febrero que el mismo Homs remitió al editor de El Estandarte Católico ${ }^{17}$, éste reconocía que "había encargado al P. Villalón, de nuestra compañía, enterarse de los artículos del señor don Crescente Errázuriz sobre el P. Luis de Valdivia i responder a ellos"18. Villalón ${ }^{19}$ se encontraba por entonces en la residencia de Valparaíso y supo de su nuevo encargo hacia finales de enero. Una semana después, el 1 de febrero, satisfizo el mandato de Homs y le envió los resultados en una carta que El Estandarte Católico publicó en tres partes.

A todas luces, Villalón era hombre interesado en la historia chilena y bien versado en ella. Según Errázuriz, poseía una "reconocida virtud, se le consideraba un ejemplo de santidad; veíase su confesonario rodeado de gente piadosa; se escuchaba, en fin su palabra como un oráculo. Siendo las cosas así, se le tenía también como casi infalible y de una inteligencia superior" ${ }^{20}$. Debió pasar muchas horas leyendo las páginas de las crónicas coloniales y desde luego debió repasar con especial detenimiento las de sus antiguos correligionarios. En 1877, a escasas fechas de la Pacificación de la Araucanía, las opiniones de Villalón no diferían en exceso de las de Alonso de Ovalle, Nicolás del Techo, Pedro Lozano o Miguel de Olivares. Como explicaba a Homs (a quien consideraba tan recientemente llegado a Chile que aún debía desconocer parcelas importantes de su pasado), "la historia de la conquista es la historia de una guerra de exterminio i casi sin tregua entre los

16 Así lo asegura en una aclaración hológrafa añadida a uno de los documentos citados a continuación: "Esta nota es del P. Baltasar Homs, por cuya orden exclusiva se emprendió la polémica sobre el P. Luis de Valdivia con D. Crescente Errázuriz. Esto me consta como consultor que era aquel año del Colegio de S. Ignacio y por correspondencia del P. Homs conmigo desde Valparaíso. F. Ginebra". Este P. Homs nació el 18 de enero de 1831 en Valls y murió el 12 de enero de 1881. Entró en la Compañía el 16 de marzo de 1852 y se ordenó el 24 de agosto de 1861.

${ }^{17}$ No deja de tener mérito haberlo hecho, puesto que Errázuriz formaba parte fundamental de aquella publicación periódica nacida en 1874-1875. Véase ERRÁZURIZ. Algo de lo que he visto, cap. 21.

${ }^{18}$ Esta carta fue publicada en El Estandarte Católico precediendo al primer escrito de Villalón en defensa de Valdivia. He consultado todos los escritos que dicho periódico publicase al jesuita sobre este tema en un volumen donde alguien unió los recortes con el título El P. Luis de Valdivia. Polémica ventilada entre el presbitero D. Crescente Errázuriz i el padre S. J. Zoilo Villalón entre febrero y mayo de 1877, que se encuentra en ACSI, caja 2/J/297, carp. 10. ERRÁZURIZ. Algo de lo que he visto, p. 211, recordaba cómo "con toda solemnidad envió a El Estandarte Católico el P. Homs, superior de los jesuítas en Chile, el 17 de febrero de 1877, una larguísima carta que, en refutación de mis artículos, le escribía desde Valparaíso el P. Villalón y que se publicó en el diario durante varios días".

${ }^{19}$ Zoilo Villalón Sabbas nació el 5 de diciembre de 1823 en Santiago de Chile y murió el 30 de noviembre de 1881. Entró en la Compañía el 25 de mayo de 1862, siendo ya sacerdote.

${ }^{20}$ ERrÁZURIZ. Algo de lo que he visto, p. 211. 
españoles i los araucanos", a quienes apreciaba como "el pueblo mas amante de su independencia i mas valiente que encontraron los europeos en toda la América; pero a la vez el pueblo mas reflexivo". La predicación del Evangelio los hubiera ganado fácilmente para los bienes superiores de la Fe y la civilización, pero el empleo de las armas para "arrebatarle su independencia i esclavizarlo" los había convertido en el más acérrimo enemigo. Lamentablemente, "la codicia i la ambicion de los conquistadores" había inclinado la balanza de la Historia hacia esta segunda opción, condenando Chile a una guerra inacabable sobre cuyas cenizas difícilmente podría florecer una iglesia nueva ${ }^{21}$.

Pero un hombre luchó por invertir esta situación: Luis de Valdivia, con un plan de pacificación cuyos puntos principales (detención de la guerra y abolición del servicio personal y la esclavitud) se oponían a los "intereses" de quienes aprobaban aquel statu quo. Según Villalón, "desde que conozco los anales de mi patria, siempre he creído que el Padre Luis de Valdivia constituía una de las mas puras glorias que las jeneraciones de los conquistadores legaron a las venideras i a la historia". Lo tenía por "un jenio y un santo" que lo sacrificó todo "por la realizacion de un proyecto que habría hecho desaparecer de nuestro suelo la barbarie mas há de dos siglos atrás, i redimido a los indios de las reducciones de la opresión a que los condenaba la codicia de los españoles". Generaciones de hombres habían afirmado lo mismo de él, la Compañía lo había incluido entre sus "venerables varones" y, según Villalón afirmaba, el proceso de su beatificación estuvo a punto de abrirse justo antes de que la expulsión de los jesuitas de los dominios españoles lo frenase. ¿Podían las diatribas de Errázuriz sobreponerse al peso de la tradición? Desde luego que no, pero si ella misma no bastase para demostrar la inocencia de Valdivia, se podría conseguir analizando la debilidad intrínseca de los argumentos de Errázuriz, que lo acusaba de ambicioso por haber pretendido el obispado de Concepción y de haber promocionado a un gobernador supuestamente anticlerical como Alonso de Ribera, todo falacias ${ }^{22}$.

Según Errázuriz, "no es posible formarse hoy idea de la impresión que entre los numerosos amigos de los jesuitas produjo la carta del P. Villalón”. Recordaba con amargura cómo "casi nadie se había fijado en mis artículos, y de repente todos supieron y nadie puso en duda que yo había cometido el delito de calumniar la gloria más pura de la Compañía en Chile; la de un hombre a quien los cronistas alababan sin reserva y a quien los historiadores de la Compañía casi colocaban en el número de los santos". Tal aberración sólo podía pagarse a un precio: "todos se

${ }^{21}$ El P. Luis de Valdivia, p. 9.

${ }^{22}$ Ibid., pp. 2-4. 
pusieron contra mí y los más moderados lamentaban mi error". Pese a todo, Errázuriz "seguro y cierto estaba de pulverizarlos [los escritos de Villalón], porque en las numerosas polémicas que hasta entonces había sostenido, jamás un adversario se había puesto más inerte en mis manos". La razón: él había trabajado con las intachables copias de documentos originales traídas desde España por Diego Barros Arana y Benjamín Vicuña Mackenna, a la luz de las cuales "era fácil conocer y corregir los errores de los cronistas". Puesto que, en su opinión, "el P. Zoilo se limitó por su parte a oponer a aquellos documentos, los pobres textos" de las historias coloniales, resultaría "sencillísimo" refutar todos sus asertos. Desde su punto de vista, así lo hizo en "cinco largos artículos", publicados asimismo en El Estandarte durante el mes de marzo y cuyo objetivo era muy claro: "probar mis primitivas afirmaciones" ${ }^{\prime 23}$.

Desde ese momento, el debate se enquistó. Ni Villalón ni Errázuriz estuvieron realmente dispuestos a escuchar las razones del otro. Su discusión terminó perdiéndose por los senderos de la arrogancia y en temas relativamente secundarios como las aspiraciones de Valdivia a ser designado obispo de La Imperial, que habría pretendido satisfacer solicitando en Madrid lo que ambos denominaban una "carta de ruego y encargo", es decir, una de las cédulas que los reyes enviaban a los cabildos catedralicios en sede vacante para que aceptasen como prelados a quienes ellos y el Consejo de Indias hubiesen elegido para gobernarlos en virtud de las prerrogativas del patronato regio antes de que se publicase la sanción papal definitiva. Llegados a tal punto, el adjetivo regalista aplicado a Valdivia no podía tardar en aparecer y, en ejemplo supremo de hasta dónde se desvió por las ramas aquella disputa, Villalón intentó despejar cualquier crítica en dicho sentido aduciendo toda una serie de argumentos entre los que causó especial revuelo una comparación con el actual arzobispo de Santiago, don Rafael Valentín Valdivieso, cuyo episcopado había comenzado también con una carta de ruego y encargo, pese a lo cual nadie podría tacharlo de regalista. ¿Acaso osaría algún sucedáneo de Errázuriz espetar algo parecido dentro de dos siglos a tan ilustre varón? ${ }^{24}$

Como puede suponerse, esta referencia causó no pocos problemas a Villalón. Disgustó a más de uno y ofendió especialmente, como no podía ser de otra forma, al propio Valdivieso. Parece que fue hacia finales de abril cuando el jesuita tomó

23 ERrÁZURIz. Algo de lo que he visto, pp. 211-13.

${ }^{24}$ El P. Luis de Valdivia, p. 6. En realidad, esta referencia a Valdivieso incluía una segunda intención velada y de dureza notable, puesto que Valdivieso era el tío materno de Errázuriz y había cuidado de él durante su infancia después de que el padre de éste muriese prematuramente. ERRÁZURIZ. Algo de lo que he visto, pp. 99-106, trata de ello. 
conciencia de la gravedad que podía llegar a adquirir la situación. Escribió entonces a su amigo José Hipólito Salas, obispo de Concepción ${ }^{25}$, para pedir consejo y éste le contestó casi dos semanas después, el 2 de mayo, por partida doble, con lo que un documento algo posterior calificó como una "respuesta mostrable" y otra "respuesta confidencial", mucho más jugosa, desde luego. La primera, más extensa, alababa a Villalón por su defensa de Valdivia con la convicción de que en ella no había ofensa alguna a Valdivieso ni voluntad siquiera de esbozarla ${ }^{26}$. La segunda, más breve (por su carácter privado podía abandonar los convencionalismos retóricos), apuntaba en la misma dirección empleando palabras más libres: "Has llevado los miramientos i las deferencias a tu contendor hasta su extremo limite i nada has dicho que pueda racionalmene herir al Venerable $\mathrm{Sr}$ Arzobispo". En tal sentido, podía quedar tranquilo, "porque, cumplido el deber, el corazón queda lijero i los enojos i enfados de los hombres no pueden alcanzar a quitarte ese tesoro de la paz del alma". Nada había más importante que eso, pensaba Salas, que dio a Villalón su autorización para que presentase a Valdivieso la otra carta que le había escrito, la "mostrable", si deseaba "satisfacer al Sr Arzobispo", aunque no se lo recomendaba. La primera razón: "que no soi yo ahora, según creo, el hombre de las confianzas del Sr Arzobispo, ni su deferencia a mis opiniones ha cambiado jamas las suias". Mas, sobre todo, "[i]con qué fin esponerte a recomenciones por pecados que no tienes?" La mejor orientación que podía darle se podía resumir en "dos palabras": "has cumplido tu deber i bien. Eso basta. Dios hará lo demas i la pequeña tempestad pasará. Esta en la esperanza de tu viejo amigo y maestro" $"$.

A despecho de las recomendaciones de Salas, Villalón no quiso dejar estar el asunto y se decidió a dirigirse por escrito al arzobispo Valdivieso. El 16 de mayo terminó una carta en la que le reconocía que, por "sujetos respetables i bien informados", había sabido que "V.S.R. habia tenido a mal la alusion hecha a su persona en lo que escribí por encargo de mi superior sobre el P. Vald., i que aun habia creido que en alguna manera lo presentaba como regalista". Afirmaba haber sentido "vivamente" haberle causado "tal pesadumbre", pero también que jamás había pretendido ofenderlo de manera alguna. Es más, "ni me imajiné que esa alusion hubiera de producir tan lamentable resultado, ni ha entrado de modo $\mathrm{al}^{\circ} \mathrm{en}$ mi intencion hacer a VSIR tan injusto y absurdo cargo". Habría querido decírselo

${ }^{25}$ Aparte de la amistad que los unía, la decisión tuvo poco de casual. Salas ya había escrito una defensa apasionada de Valdivia en su Memoria sobre el servicio personal de los Indijenas $i$ su abolición y, asimismo, había comenzado su pontificado con una carta de ruego y encargo.

${ }^{26}$ ACSI, caja 2/J/294, carp. 24, doc. 2; Salas a Villalón, Concepción, 2 de mayo de 1877.

27 ACSI, caja 2/J/294, carp. 24, doc. 3; Salas a Villalón, Concepción, 2 de mayo de 1877. 
en persona, pero no había podido: "le confesaré que me he sentido débil para arrastrar la dolorosa inpresion que me causaria oirle hacerme cargos por lo que ha sucedido". Para terminar, y nunca sin perder ese tono autoflagelante con el que pretendía captar la benevolencia de Valdivieso, Villalón le rogó que tuviese la bondad de leer la carta del obispo Salas, que efectivamente adjuntó, "pues espero podrá contribuir a que se persuada que no es verosímil vaya nadie por lo que he escrito a pensar lo que VSR i R teme" ${ }^{28}$.

La carta logró su objetivo. El día 22, Valdivieso firmó la respuesta, que comenzaba con un "mi apreciado amigo" que anunciaba su talante conciliador, después desarrollado: "me dolió mucho que se me hiciera cómplice de ésta falta; pero esto no quiere decir que por un momento sospechara siquiera que en el ánimo suyo hubiese el mas remoto designio de ofenderme". Esto último puede ponerse en tela de juicio, mucho más contemplando la extensa parrafada que le escribió a continuación para explicar los motivos por los que no podía considerársele regalista (jaunque se disculpaba por redactar con brevedad a causa de estar "mui molestado por la tos" después de haber guardado cama!), pero no hay duda acerca de que Valdivieso había aceptado las disculpas de Villalón y estaba dispuesto a pasar página ${ }^{29}$. El jesuita lo agradeció profundamente en una segunda carta que comenzó llamando a Valdivieso "mi venerado i amado señor" y terminó besándole las manos y denominándose a sí mismo "su mui afecto servidor i capellan". Entre medias, como puede imaginarse, una completa aceptación de los argumentos del Arzobispo y una amarga lamentación por no haberlos conocido antes de haber errado con aquel infortunado comentario primero ${ }^{30}$.

Años después, el P. Francisco Ginebra escribió un comentario muy significativo al final de aquel documento: "Esta carta del P. Villalón al Ilmo. Sr. Valdivieso disgustó al P. Homs, entonces Superior de la Misión. Así me lo manifestó, añadiendo que en ella había hecho poco menos que cantar la palinodia". Ese estilo adocenado que el obispo Salas había desaconsejado disgustó a Homs, principal promotor de la respuesta jesuítica a Errázuriz, pero contribuyó decisivamente a clausurar un posible enfrentamiento con Valdivieso. Podría pensarse que eso permitiría a Villalón centrarse de nuevo en su disputa intelectual con Errázuriz, pero parece que, en vez de eso, causó el efecto contrario, pues en aquel mismo mes de mayo finalizó el fuego cruzado entre ambos en las páginas de El Estandarte Católico. Según declararía con posterioridad, Errázuriz se había cansado de una

\footnotetext{
${ }^{28}$ ACSI, caja 2/J/294, carp. 24, doc. 4; Villalón a Valdivieso, Santiago, 16 de mayo de 1877.

${ }^{29}$ ACSI, caja 2/J/294, carp. 24, doc. 5; Valdivieso a Villalón, Santiago, 22 de mayo de 1877.

${ }^{30}$ ACSI, caja 2/J/294, carp. 24, doc. 7; Villalón a Valdivieso, Santiago, 27 de mayo de 1877.
} 
disputa en la que, para su adversario, "lo importante era que [...] pusiese [punto y final] yo también; que no hablase más; que quedara él encima" ". Por su parte, los jesuitas parecían haber llegado a la conclusión de que, antes de seguir escribiendo, necesitaban disponer de una documentación más completa que la que tenían entonces en su poder. Así, sus futuros argumentos podrían ampararse en su autoridad y no en comparaciones más o menos exactas con prelados contemporáneos. Presumiblemente en 1877, Villalón y Homs escogieron los documentos más importantes que deberían localizarse y transcribirse en Sevilla ${ }^{32}$ y en 1878 viajó a Chile el volumen de copias que aún conserva el colegio jesuita de Santiago $^{33}$. Sin embargo, nunca sirvieron para que Villalón escribiese ninguna refutación más a los artículos de de Errázuriz. Las razones se nos escapan, pero quizás no fueran ajenas a ella la circunstancia de que su muerte, acaecida en $1881^{34}$, se hallaba ya próxima.

Las tensiones entre Crescente Errázuriz y la Compañía de Jesús conocieron así un tiempo de paréntesis hasta que volvieron a encenderse cuando se aproximó la fecha de publicación de dos importantes libros de aquél: Seis años en la historia de Chile, que estudiaba el período comprendido entre 1598 y 1604, e Historia de Chile durante los gobiernos de Merlo de la Fuente, Jaraquemada y García Ramón $^{35}$, que continuaba cronológicamente al anterior hasta las vísperas mismas de la Guerra Defensiva. Ello impidió a Errázuriz exponer (y quizás no tomase esta decisión por casualidad) el desarrollo de la política valdiviana en Chile, pero le permitió volver sobre el tema de las negociaciones del jesuita en la Corte y, aun manifestando la importancia que tuvieron en la historia chilena, no dejó escapar la oportunidad de referirse de nuevo al tema del obispado, repitiendo uno por uno

${ }^{31}$ ERrÁZuriz. Algo de lo que he visto, p. 216.

32 ACSI, caja 2/J/294, carp. 24, doc. 10; "Documentos que convendría pedir a Europa relativos al P. Luis de Valdivia", s.f. [c. 1877].

33 El ya mencionado ACSI, caja 2/J/294, carp. 22; Archivo de Indias. Documentos sobre el P. Valdivia traídos (á lo que parece) hacia 1878, después de la polémica del P. Zoilo Villalón con D. Crescente Errázuriz. Figuran en él la carta de Montesclaros a Felipe III (Lima, 30 de abril de 1610) en que el Virrey informa de la animadversión de Pérez de Espinosa hacia la Compañía, los memoriales de Luis de Valdivia y Lorenzo del Salto en la Corte, la carta de aquél a Pedro de Ledesma y el compendio que publicó en 1611 en Lima en defensa de la Guerra Defensiva, varias reales cédulas sobre esta materia de 1610 y 1616, una carta de Valdivia de septiembre de 1612, una información de la época del desastre de Elicura y la pequeña documentación sobre un pleito contra los sargentos Meléndez y Torres. Esta documentación se encuentra hoy casi toda en AGI, Patronato, leg. 229.

${ }^{34}$ Véase supra nota 15.

${ }^{35}$ ERrÁzuriz, C. (1908). Seis años en la historia de Chile. 23 de diciembre de 1598-9 de abril de 1605. Santiago de Chile: Imprenta Cervantes y (1908). Historia de Chile durante los gobiernos de García Ramón, Merlo de la Fuente y Jaraquemada. Santiago: Imprenta Cervantes. 
todos sus argumentos de 1876-1877. A todas luces, nada de lo que Villalón le replicó entonces había llegado a convencerlo. Según llegaría a escribir, aquella polémica sólo sirvió para enfriar "notablemente las relaciones, nunca muy íntimas, de la mayor parte del clero con los jesuitas"36.

La documentación que guarda el Archivo del Colegio de San Ignacio referente a este segundo enfrentamiento se conserva en la carpeta 25 de la caja 2/J/294 y consta de una cronología de la polémica, una Muestra del modo cómo se han interpretado algunos documentos en los capitulos manuscritos que tratan del P. Valdivia, un acta de la entrevista entre Hernández y Errázuriz y otra de una conversación mantenida por el P. Silvestre Correa, S.I., y fray Juan Alberto Aguirre, O.P., unos "Cargos que sin prueba suficiente se hacen al P. Valdivia, S.I." y varias cartas remitidas entre Errázuriz y Hernández y entre Hernández y sus superiores. Suman diez documentos en total, con los que se pueden reconstruir muchos de los pormenores de esta segunda parte del debate.

Según la cronología antes mencionada ${ }^{37}$, guía utilísima para orientarse en estos acontecimientos, todo comenzó a fines de 1907, año en el que Errázuriz recibió del Gobierno de la República de Chile la importante cantidad de 10.000 pesos para publicar su libro. Por entonces, Errázuriz había entrado en la Orden de Santo Domingo, cuyos superiores en Chile, conscientes de cómo habían recibido los jesuitas las críticas hacia Valdivia décadas atrás, intentaron suavizar el posible conflicto que se preveía y que no deseaban en absoluto. El prior del convento dominico de Nuestra Señora del Rosario remitió a José Barrachina, superior jesuita en Santiago ${ }^{38}$, una copia de las cuartillas del manuscrito en que se analizaba la Guerra Defensiva. Éste ya no contaba con Villalón para oponerse a Errázuriz, pero no le costó encontrar a quien lo sustituyese. En concreto, pensó en Pablo Hernández ${ }^{39}$, un importante historiador jesuita, recordado fundamentalmente por un suculento capolavoro sobre las reducciones guaraníes de la Compañía de Jesús, durante mucho tiempo la mejor obra sobre la materia ${ }^{40}$. Lamentablemente para la

${ }^{36}$ ERrÁzuriz. Algo de lo que he visto, p. 209.

37 ACSI, caja, 2/J/294, carp. 25, doc. 2. Fue redactada por Pablo Hernández en Santiago, 20 de abril de 1910.

${ }^{38}$ Nació en Alicante el 24 de marzo de 1856 y murió en Chile el 7 de junio de 1929. Entró en la Compañía el 4 de mayo de 1873 y se ordenó sacerdote el 31 de julio de 1890.

39 Nació el 9 de octubre de 1852 en Teruel y murió el 16 de febrero de 1921. Entró en la Compañía el 4 de febrero de 1872 y se ordenó sacerdote el 8 de septiembre de 1887.

40 Hernández, P. (1913). Organización social de las doctrinas guaranies de la Compañía de Jesús, 2 vols., Gustavo Gili, Barcelona. Publicó algunos libros más, ajenos a la materia que nos ocupa, y que, por tanto, considero ocioso reseñar. 
Compañía de Jesús (o, por lo menos, para la memoria del P. Luis de Valdivia), su actuación resultaría menos lucida en este caso particular y poco podría oponerse a la consistencia de la obra de Errázuriz.

Hernández recibió las cuartillas enviadas por Barrachina a finales de año, mientras se encontraba en Concepción. Debía señalar todos los errores que encontrase en ellas para comunicarlo a la Orden de Predicadores y con este fin decidió desplazarse a comienzos de 1908 hasta Santiago, "principalmente para estudiar ese punto en los Archivos". Después de un primer análisis, Hernández entendía que Errázuriz había lanzado tres cargos injustos contra Valdivia:

1. "Que fue criminal contra la Iglesia y contra su conciencia, empeñándose en ejercer coacción sobre el Obispo de Santiago.

2. Que anduvo negociando un Obispado para sí.

3. Que en aconsejar que viniese Alonso de Rivera por Gobernador de Chile, cometió una y aún muchas graves y vituperables faltas que no se pueden justificar, y todas caen sobre él, porque él fue la única causa del nobramiento".

Puede observarse que son las mismas conclusiones a las que había llegado Villalón en $1877^{41}$, por lo que si el juicio de Errázuriz sobre Valdivia había variado poco en todo aquel tiempo, la defensa derivada de los jesuitas tampoco experimentaría la menor transformación en lo esencial, aunque Hernández se veía capaz de añadir observaciones nuevas. Así, acusaba a Errázuriz de haber presentado a Valdivia como "hombre poseído de insaciable ambición" o "sacrílego y transgresor de sus votos", "ignorante de lo que por oficio debía saber", "alucinado, que no acierta á ver lo mismo que toca con las manos", "engañador indigno de crédito" o "infiel á sus compromisos é ingrato á sus bienhechores"42. En resumidas cuentas, "ni el impío Barros Arana, que aprovecha toda ocasión de tildar, con razón ó sin ella, al clero y á las Órdenes religiosas, ha pintado, ni con mucho, tan criminal, despreciable y destestable al P. Valdivia". Frente a semejante panorama, Hernández no tardó en llegar a una conclusión taxativa y que no puede sorprender conociendo los precedentes: "Hallo que se tendría que mudar todo". Según sus estimaciones, cambio tan drástico y descomunal requeriría no menos de

\footnotetext{
${ }^{41}$ El mismo Hernández subraya el paralelismo de su análisis con el de Villalón: "Estos cargos son justamente los que en los artículos de don Crescente Errázuriz del año 1877 reparó ya el P. Zoilo Villalón, S.I., de buena memoria".

${ }^{42}$ ACSI, caja 2/J/294, carp. 25, doc. 6; "Cargos que sin prueba suficiente se hacen al P. Valdivia, S.I.", s.f. [1908].
} 
cien páginas de observaciones, así que Barrachina encargó a Hernández que las redactase él mismo ${ }^{43}$.

Éste, "para hacer las cosas bien”, optó por comenzar concertando una entrevista con Errázuriz, que tuvo lugar el 9 de febrero. Todo pasó deprisa. Hernández concibió el plan aquella misma mañana y, sin pensarlo dos veces, se dirigió a la Recoleta dominica, donde llegó hacia las 12 de la mañana. Sólo pretendía informar al prior de su deseo, pues suponía a Errázuriz en Apoquindo, aquejado entonces de una seria parálisis. Sin embargo, el prior lo informó de que Errázuriz se encontraba allí y de que, si quería hablar con él, podía hacerlo en aquel mismo momento en la biblioteca. El jesuita no dejó pasar la oportunidad y mantuvo con Errázuriz una conversación de aproximadamente tres cuartos de hora en la que, después de las cortesías de rigor, Valdivia se erigió en el tema principal. Errázuriz le confirmó que, gracias a los apoyos personales y económicos que había recibido, iba a publicar aquel mismo año una obra que abarcaba el período entre 1605 y 1611, es decir, el lapso comprendido entre el final del primer gobierno de Alonso de Ribera y los comienzos del segundo. Todo estaba listo para llevarlo a la imprenta excepto los últimos ocho capítulos, que eran los que había remitido a los jesuitas para conocer su opinión sobre ellos. Apuntaba incluso que tenía ya escrito lo que concernía a la Guerra Defensiva, aunque no aparecería entonces. Hernández le inquirió qué pretendía exactamente de ellos y el dominico respondió que había "cercenado" y "dulcificado" lo que había escrito sobre el tema décadas atrás, intentado hacer ver, sobre todo, que "los graves errores y deslices del P. Valdivia" (que, evidentemente, daba por hechos) correspondieron esencialmente a él mismo y carecieron de la aprobación de sus superiores: "desearía que cuanto hubiera que advertir en esto, me lo dijesen para enmendarlo: ya que en lo sustancial nada puedo cambiar" ${ }^{\prime 4}$.

Frente a semejante declaración, tan significativa, Hernández le espetó si la polémica con Villalón le había hecho reconsiderar en algo su postura. La respuesta volvió demoledora: "no me hicieron ningún efecto". Ante esto había que mostrar firmeza y Hernández no dudó en hacerlo.

Yo le he dicho que si se juzga necesario, nosotros desharemos el error, como es claro, mostrando las cosas en que, según nuestro concepto, se equivoca el autor. Con esta ocasión he insinuado la idea de que cualquier autor, por interés de la verdad histórica y aun por propia conveniencia, está

${ }^{43}$ Cronología de la polémica.

44 ACSI, caja 2/J/294, carp. 25, doc. 5; "Relato de una entrevista del P. Pablo Hernández, S.I., con el P. Fr. Crescente Errázuriz, O.P., viernes 7 de febrero de 1908”. 
obligado a no afirmar sino lo que prueban los documentos, tratando como cierto lo que en ellos es cierto, y como sólo dudoso ó conjetural lo que en ellos no se contiene claramente: y he dicho que á esta obligación se añade obligación de justicia cuanto está de por medio la fama de una persona.

Lógicamente, Errázuriz se mostró de acuerdo en todo aquello, aunque a todas luces consideraba que los documentos disponibles certificaban todos sus asertos. Hernández le recriminó que los que se conservaban no permitían llegar a conclusiones tan categóricas, a lo que astutamente retó a los jesuitas a que presentasen nuevos papeles que demostrasen su postura. Si tal hacían, estaba dispuesto a variar la suya, lo que obviamente quería decir que en la situación entonces presente nada le haría variar lo que había escrito. "No, Padre," concluyó, "en la sustancia estoy resuelto á no mudar nada, lo he estudiado muchísimos años: no digo más que lo que dicen los documentos, y estoy resuelto á no cambiar: es mi convicción" 45 .

Hernández se disponía a marcharse. Saltaba a la vista que no podía llegar a ningún acuerdo con Errázuriz, pero, antes de hacerlo, decidió sugerirle que, si persistía en culpar a Valdivia por solicitar la carta de ruego y encargo, debería extender su juicio a "todos los obispos antiguos de América" y considerarlos sin excepción "prevaricadores, malos católicos [y] malos sacerdotes". Errázuriz se encogió de hombros y admitió: "aunque fueran todos, ¿qué?". La particularización de aquella cuestión en el arzobispo Valdivieso, que ya crease problemas a Villalón, hizo subir el tono de la discusión, que llegó a ser "tan fuerte que ha sido preciso dejarlo". Todo estaba dicho, así que "con esto me levanté y despedí con el afecto posible, y él con alguna frialdad"46. Esa misma tarde, ya en el colegio de San Ignacio, Hernández escribió el acta de aquella reunión para que quedase constancia de cuanto había sucedido. Es una pena que no se conserve documento análogo de la pluma de Errázuriz, que apenas trata de este segundo enfrentamiento con los jesuitas en sus memorias ${ }^{47}$, pero al menos la interpretación que de los hechos hizo el jesuita nos permite comprender las resoluciones que tomó en aquel preciso momento.

Puesto que nada le restaba por hacer en Santiago, Hernández volvió a su residencia en Concepción, desde donde escribió dos cartas a Estanislao Soler,

45 Ídem.

46 Ídem.

47 ERrÁzURIZ. Algo de lo que he visto, p. 214, apenas trata esta segunda parte de la polémica como una mera reedición de lo que había sucedido en 1877. Considerando sus asertos más que demostrados, no quiso otorgarle ni mediana importancia. 
rector del Colegio de Santiago ${ }^{48}$, en las que lo ponía en conocimiento del callejón sin salida en que se había atascado aquella cuestión. La primera de ellas iba acompañada de los ocho capítulos de la discordia, sin corregir, dado que "el autor está resuelto a no mudar la sustancia de dichos capítulos, en los que se han conservado los mismos asertos sin prueba competente y gravemente injuriosos a la fama del P. Valdivia que ya le hizo notar en 1877 el P. Zoilo Villalón, S.I., de buena memoria". En cualquier caso, y pese a que parecía que poco más podría hacerse en aquel asunto, Hernández se declaró voluntario para continuar contribuyendo a "la interesante tarea de esclarecer los puntos históricos relativos al P. Luis de Valdivia"49. Tres días después, trató de nuevo el tema con mayor prolijidad y reiteró la imposibilidad de convencer a Errázuriz para que reconsiderase sus palabras, escritas desde la ignorancia de lo que respetables cronistas jesuitas habían afirmado en contrario e interpretando pésimamente "una colección corta e incompleta de documentos, sin haber estudiado los originales (no obstante que en gran parte existen hoy todavía en el Archivo de Indias de Sevilla) y contentándose sólo con algunas copias elegidas y traídas por otros". Tan frágiles eran las bases de aquellas "convicciones arraigadas" que alegaba Errázuriz para no variar un ápice su escrito, que no sólo contenía "propias impresiones", sino "fallos de juez". Y como, ya sin ocultar su rabia, proclamaba que

no se puede poner en tela de juicio que [a Valdivia] le asiste el derecho que tiene cualquier incógnito, aunque sea el ínfimo de los hombres, de no ser presentado como un criminal, transgresor de sus deberes y de sus votos hechos á Dios, ignorante, hipócrita y soberbio, mientras no se prueben las acusaciones suficientemente: juzgo que la publicación del dicho manuscrito será un verdadero cargo de conciencia para quien la haga.

Pero la Compañía no debía conformarse con ello. La causa merecía que se presentase una protesta formal antes los superiores inmediatos de Errázuriz en Chile y, si esa acción no fructificase, debería transladarse incluso a Roma y acudirse al Padre General de la Orden de Predicadores. Cuando la causa de la verdad saliese vencedora, cabría incluso publicar un estudio sobre la obra del P. Errázuriz, de lo cual "podrá él perder algún crédito, pero se satisfará, siquiera en parte, á la injuria irrogada al P. Valdivia"50.

48 Nació el 14 de mayo de 1849 en Valencia y murió el 13 de enero de 1915. Entró en la Compañía el 7 de julio de 1867 y se ordenó sacerdote el 28 de agosto de 1883.

49 ACSI, caja 2/J/294, carp. 25, doc. 4; Hernández a Soler, Concepción, 2 de marzo de 1908.

${ }^{50}$ ACSI, caja 2/J/294, carp. 25, doc. 3; Hernández a Soler, Concepción, 5 de marzo de 1908. 
Parece que Soler no estimó oportuno llegar a tales extremos y se contentó con devolver a los dominicos los famosos ocho capítulos, dando muestras visibles de su descontento por lo que en ellos había escrito. No se dignó a hacerlo en persona, por lo que designó al P. Silvestre Correa Bravo ${ }^{51}$ para que lo sustituyese y entregase en mano la documentación en la Recoleta. El 4 de abril, Correa cumplió con su incómodo cometido y se vio con el prior, fray Juan Alberto Aguirre, que intentó justificar a Errázuriz recordando su disposición a variar sus conclusiones si se le daban a conocer papeles nuevos que ofreciesen una visión distinta a la suya. Correa se disculpó por su ignorancia al respecto; el tiempo del debate había concluido ya, aunque no venció la tentación de referir que había tenido noticia de que "en el Archivo de Sevilla hay un documento que desvirtúa varias de las afirmaciones del R. P. Errázuriz". Aguirre no consideró oportuno enfrascarse en aquellos asuntos, que calificó de "muy sensibles" y aun "muy contrarios" a su "cometer". Su interlocutor comprendió que se hallaba frente a persona prudente y de parecer parecido al suyo:

¿Qué fruto se saca con renovar cuestiones que vienen a agriar los ánimos entre las mismas órdenes religiosas? Harto tenemos que hacer con combatir a los enemigos de la Religión para que vengamos a combatirnos entre nosotros mismos. Además, si uno de los frutos principales que se pretenden sacar de la obra del R. P. Errázuriz es conocer los errores de la Colonia para evitarlos o en la pacificación de los indios para emplear otro sistema ¿cuándo tendrá aplicación todo eso? Hoy día no se trata de la pacificación de los indios, sino de evitar su extinción.

Aguirre asintió a las apreciaciones de Correa y hasta le preguntó qué salida podría existir para un problema que a todas luces no lo agradaba. Correa contestó que quizás el nombramiento de un tribunal neutral que analizase los escritos de Errázuriz y señalase los cambios que debiese efectuar de confirmarse las inconveniencias que Hernández señalaba. Aguirre refirió que lo consultaría con Errázuriz, lo que obviamente no pasaba de ser una cortesía con el jesuita, puesto que aquél jamás aceptaría semejante idea. El prior demostraba no sentir el menor interés por aquella burda polémica y mucho menos por ofender a ningún jesuita para imponerse en ella, pero ni por asomo pretendía dejar en la estacada a su ilustre

${ }^{51}$ Nació el 31 de diciembre de 1858 en Talca y murió el 2 de marzo de 1917. Entró en la Compañía el 20 de febrero de 1890 y aunque no se conoce con exactitud la fecha de su unción sacerdotal, se estima que debió ocurrir hacia 1899. 
correligionario. Se cerraba así un diálogo de sordos entre jesuitas y dominicos, cuyo nulo resultado abría la necesidad de otra batalla de artículos ${ }^{52}$.

La actitud de ambas partes no había variado esencialmente desde que se abriese aquel debate, cuya significación había variado notablemente respecto a treinta años atrás. Las palabras de Correa ofrecen varias claves al respecto. En 1877, vísperas de la Pacificación de la Araucanía, la experiencia de Luis de Valdivia gozaba de un evidente interés por su capacidad para convertirse en modelo a seguir o rechazar en el esfuerzo por integrar el sur del Bío-Bío dentro de la jurisdicción de la República, ya más libre para afrontarlo conforme el conflicto con peruanos y bolivianos tocaba a su fin. En 1908, cuando (para bien o para mal) aquel proceso se encontraba ya concluido, la actualidad política de la Guerra Defensiva, especialmente perceptible en la obra faraónica de Barros Arana, empezaba a desvanecerse con rapidez. Como bien afirmaba Correa, urgía más por aquellas fechas el drama de la desaparición étnica o cultural de los nativos que el de su supuesta asimilación a Chile. Y mientras más se desvinculaba de la realidad chilena, el debate se enconaba más en cuestiones que en el mejor de los casos sólo pueden ser calificadas como secundarias, como la carta de ruego y encargo del obispado, si Valdivia lo pretendió o no y, en caso afirmativo, si podía ser calificado de ambicioso por ello. La disquisición histórica que inicialmente había portado lecciones aplicables al tiempo de quienes se enfrascaron en ella pasaba a convertirse en una inútil pugna entre órdenes religiosas que aburría y resultaba incómoda, por innecesaria, a muchos de sus miembros, tales como Correa o Aguirre. Con no demasiada exageración podría entenderse incluso que había degenerado en un duelo intelectual entre Hernández y Errázuriz que, por la filiación institucional de ambos y por el contenido disputado, no dejaba de salpicar a sus respectivas órdenes.

Hernández publicó fragmentadamente su primer opúsculo contra Errázuriz en el mismo 1908. Se trataba de El P. Luis de Valdivia, S. J. con nuevos documentos ${ }^{53}$, al que siguió dos años después El P. Luis de Valdivia S.I. en Madrid y Lima antes de emprender su último viaje a Chile, publicado fragmentariamente en las páginas de La Revista Católica ${ }^{54}$. Pese a su detenido análisis de los documentos que por

52 ACSI, caja 2/J/294, carp. 25, doc. 1; "Papel del P. Silvestre Correa enviado al P. Pablo Hernández por el P. Rector Estanislao Soler", Santiago, 4 de abril de 1908.

${ }^{53}$ Hernández, P. (1908). El P. Luis de Valdivia, S. J. con nuevos documentos, Santiago. En la primera página aparece el título El padre Luis de Valdivia, S. J. Propuesto para Obispo de Concepción de Chile. Estudio histórico sobre los documentos por el P. Pablo Hernández, S. J.

54 Hernández, P. (1910). El P. Luis de Valdivia S.I. en Madrid y Lima antes de emprender su último viaje á Chile. Estudio histórico sobre los documentos. Artículos publicados en la Revista 
entonces le llegaron en los dos volúmenes de copias ya referidos, las obritas de Hernández no lograron equipararse a los monumentos de Errázuriz y difícilmente hubieran podido luchar frente a ellos con eficacia. Aun así, Hernández envió a Errázuriz un ejemplar de El P. Luis de Valdivia, S. J. con nuevos documentos. En la carta que le adjuntaba, presentaba su trabajo y agradecía a Errázuriz el impulso que le había ofrecido para escribirlo. Él lo había retado a encontrar los documentos que derribasen sus teorías y allí aparecía la prueba de que lo había aceptado ${ }^{55}$. Errázuriz reaccionó de inmediato y remitió a su oponente no un simple folleto, sino los dos tomos de la polémica Historia de Chile durante los gobiernos de García Ramón, Merlo de la Fuente y Jaraquemada, recién salida de la imprenta. Según Errázuriz, "aunque no en todos los puntos entendamos las cosas de una misma manera, la diversidad de pareceres no será ciertamente obstáculo para estar siempre unidos en el deseo de la gloria de Dios y defensa de la verdad"56, si bien la confrontación de los escritos de ambos demuestra que ambos defendían verdades distintas y distantes. Los ocho capítulos sobre los que tanto habían discutido los dos historiadores habían pasado íntegros a la obra.

$$
* * *
$$

Después de haber triunfado en las crónicas coloniales, Valdivia salió derrotado en las historias republicanas. Si al libro de Errázuriz se suma todo lo que, en esta misma línea, afirmó el "impío" Diego Barros Arana en su Historia General de Chile $e^{57}$, publicada también por esas fechas, puede comprenderse que la imagen histórica del padre se derrumbase desde los altares a los que la había encumbrado la cronística jesuita colonial. Poco pudieron hacer los opúsculos de Hernández para evitarlo, igual que las bienintencionadas páginas de Domingo Amunátegui Solar ${ }^{58}$ o incluso la mismísima Historia de la Compañía de Jesús en la Asistencia de

Católica, Santiago de Chile, n. 205-210, aparecidos en febrero-abril. El ejemplar de que dispongo los reúne todos y se halla en ACSI, caja 2/J/297, carp. 5.

55 ACSI, caja 2/J/294, carp. 25, doc. 8; Hernández a Errázuriz, Concepción, 1909.

${ }^{56}$ ACSI, caja 2/J/294, carp. 25, doc. 9; Errázuriz a Hernández, Santiago, 23 de febrero de 1909.

57 Barros Arana, D. (2000). Historia general de Chile. Santiago: Dibam. Las referencias a Valdivia se encuentran fundamentalmente en los tomos III y IV. Esta historia fue la punta de lanza de lo que ha sido conocido como una "reinterpretación anticlerical del pasado chileno": WoLL, A. (1973). «The Catholic Historian in Nineteenth Century Chile». The Americas. A quarterly review of inter-American cultural History, XXXIII-3, pp. 470-489. Este valioso artículo ofrece algunas referencias interesantes a la material que ahora nos ocupa.

58 AmunÁtegui Solar, D. (1934). «Un apóstol de carne y hueso» en Jesuitas, gobernantes, militares y escritores. Santiago: Ercilla, pp. 17-34, de quien dice que "pocas figuras se conocen más interesantes y simpáticas en la historia de Chile, que la del jesuita Luis de Valdivia", a quien define como "abnegado, valiente, perspicaz"... 
España y América, del P. Antonio Astrain, a pesar de representar el mayor esfuerzo hecho jamás por escribir una historia de la Guerra Defensiva aferrándose al contenido de la documentación, entre ella la del archivo romano de los jesuitas, cuya documentación desempolvó con eficacia insuperable ${ }^{59}$. Es más, paradójicamente, el propio Errázuriz creyó encontrar en los escritos de Astrain una confirmación de sus teorías y así lo proclamó en un artículo de 1914 que tituló significativamente "fin de una antigua polémica"

La victoria de Errázuriz y Barros Arana significó la apertura de un período en el que Valdivia y su proyecto político fueron mal estudiados. Grosso modo este momento es encuadrable dentro de la primera mitad del siglo XX y señaló claramente el momento de peor valoración del jesuita en los cerca de cuatro siglos que éste lleva siendo atención de la historiografía ${ }^{61}$. Habría que esperar a 1960 para que José Armando de Ramón Folch llamase la atención del mundo académico sobre la necesidad de replantear los estudios sobre Valdivia ${ }^{62} \mathrm{y}$, por supuesto, tendrían que pasar décadas hasta que su mensaje tomase forma completamente y se sobrepusiese a esa imagen excesivamente negativa creada a comienzos del siglo XX. Hoy, afortunadamente, ese proceso de normalización de los estudios valdivianos parece consolidado gracias a que en él se han ido jalonando los estudios del ya mencionado Eugene H. Körth, Walter Hanisch Espíndola, Horacio Zapater Equioiz, Rolf G. Foerster, Pilar Latasa Vassallo, Paolo Broggio o Javier Burrieza Sánchez ${ }^{63}$ y sigue avanzando gracias a las iniciativas como la nueva

59 Astrain, A. (1902-1925). Historia de la Compañia de Jesús en la Asistencia de España y América. Madrid: Sucesores de Rivadeneyra.

${ }^{60}$ ErRÁZURIZ, C. (1914). «Fin de una antigua polémica. El P. Luis de Valdivia y el proyecto de guerra defensiva». Revista Chilena de Historia y Geografia, 11.

${ }^{61}$ Un eco de este resultado se encuentra, por ejemplo, en la voluminosa obra de ENCINA, F. A. (1983-1984 [1948]). Historia de Chile: texto original completo. Santiago: Ercilla.

${ }^{62}$ Fue en su discurso de ingreso en la Academia Chilena de la Historia, publicado al año siguiente como (1961). «El pensamiento político-social del P. Luis de Valdivia». Boletín de la Academia Chilena de la Historia, 64, pp. 85-106.

${ }^{63}$ Hanisch Espíndola, W. (1974). Historia de la Compañia de Jesús en Chile, Francisco de Aguirre, Buenos Aires-Santiago de Chile y (1967). «La familia del P. Luis de Valdivia en Granada». Boletín de la Academia Chilena de la Historia, 77, pp. 129-46. ZAPATER EQUiolz, H. (1992). La búsqueda de la paz en la guerra de Arauco: padre Luis de Valdivia, Santiago: Andrés Bello. FoERSTER, R. G. (1996). Jesuitas y mapuches, 1593-1767. Santiago: Universitaria. LATASA VASSALlo, P. (1997). Administración virreinal en el Perú. El gobierno del marqués de Montesclaros (1607-1615), Madrid: Fundación Ramón Areces. BrogGio, P. (2004). Evangelizzare il mondo. Le missioni della Compagnia di Gesù tra Europa e America (secoli XVI-XVII). Roma: Carocci, pp. 21118 y (2005). «I gesuiti come mediatori nella guerra de'arauco: il padre Luis de Valdivia e il sistema dei Parlamentos de indios (XVII secolo)». Archivum Historicum Societatis Iesu, 147, pp. 57-89. 
edición de la crónica de Tribaldos de Toledo, preparada por $\mathrm{M}^{\mathrm{a}}$ Isabel Viforcos Marinas $^{64}$.

\section{APÉNDICE DOCUMENTAL}

ACSI, caja 2/J/294, carp. 25, doc. 5: "Relato de una entrevista del P. Pablo Hernández, S.I. con el P. Fr. Crescente Errázuriz, O.P., viernes 7 de febrero de 1908”.

La idea de ir a ver al P. Crescente ha tenido origen hoy mismo. Hace como 25 días, estando en Concepción, recibí una tarjeta del P. Rector del colegio de San Ignacio, Estanislao Soler, S.I. en que me decía: "Enero 13 1907... Por el correo recibirá V. R. unos capítulos de Historia de Chile enviados por el R.P. Crescente Errázuriz, O.P - Se trata en ellos la parte en que interviene nuestro Padre Valdivia: y es el caso que el P. Crescente rogado por muchos trata de reimprimir la Historia que hace años escribió, y que tanta polémica provocó con los NN. -Ahora el P. Crescente envía los capítulos predichos para que nosotros hagamos y deshgamos, corrijamos, quitemo, etc. No quiere que salga nada que no aprobemos nosotros en el susodicho asunto del P. Valdivia, en esta nueva edición. -Al R. P. Superior ha parecido, y á mí también, que uqiem mejor que todos puede encargarse de ellos es V.R. y por eso le mando esos manuscritos".

Llegaron los manuscritos el 18 de Enero; y necesitando yo tener á la vista otros libros y papeles, vine á Santiago martes 28 de enero. Terminado mi estudio, dí al R.P. Rector mi parecer, juzgando que no se podía tratar de reparos ó correcciones menores mientras no se reformase fundamentalmente la materia de los capítulos enviados, por mantenerse allí los mismos cargos que ya había demostrado el P. Zoilo Villalón S.I. al autor eran injustamente ofensivos á la fama del P. Valdivia y no probados: y que esta reforma nadie la podía hacer sino el autor, pues había de corresponder al plan general y á los antecedentes y consiguientes, y ser escrita con estilo propio é igual al resto de la obra.

Burrieza SÁnchez, J. (2004). «La antigua Compañía de Jesús (siglos XVI-XVIII)». En EGIDO, T. (coord.). Los jesuitas en España y en el mundo hispánico. Madrid: Marcial Pons, pp. 25-278 y (2007). Jesuitas en Indias: entre la utopía y el conflicto. Trabajos y misiones de la Compañia de Jesús en la América moderna. Valladolid: Universidad. De entre todas estas obras, la más importante para la Guerra Defensiva es, sin duda, el libro de Zapater, la única monografía que en puridad existe sobre el tema.

${ }^{64}$ ViforCos tocó ya el tema de la Guerra Defensiva junto a Jesús Paniagua en su estudio (1997). El humanismo jurídico en las Indias. Hernando Machado y su memorial sobre la guerra de Chile. Badajoz: Diputación. Pero su contribución más reciente ha sido el estudio y anotación de: Luis TRIBALdOS DE TOLEDO (2009), Historia general de las continuadas guerras i dificil conquista del gran reino y provincias de Chile, desde su primer descubrimiento por la nación española, en el orbe antártico, hasta la era presente, Universidad de León, Colección Tradición Clásica y Humanismo en España e Iberoamérica, León. Modestamente, espero que mi tesis doctoral, de futura publicación y también centrada en la Guerra Defensiva, contribuya en la medida de sus posibilidades a la renovación de los estudios valdivianos. 
Iba á volverme á Concepción, cuando incidentalmente me ha dicho el P. rector que el P. Crescente nunca podría corregir esos capítulos por sí mismo, pues hace tiempo se halla imposibilitado. De aquí me ha venido primero la idea de redactar yo mismo los tales capítulos como me parece que debieran ser, para facilitarle ó hacerle posible el trabajo: y luego la de visitarle para saber de él mismo con fijeza qué es lo que desea y cuál es su intención precisa, á fin de no emplear un trabajo enorme vanamente.

Llegado yo á la Recoleta dominica á las doce de la mañana, he hablado al R.P. Prior, preguntando por el P. Crescente, que ya suponía enfermo en Apoquindo y allí pensaba ir á verle: y me ha dicho que estaba aquí, é iba á verle en la biblioteca.

Nuestra conversación ha tenido lugar en la biblioteca del convento, y ha durado unos tres cuartos de hora.

Después de preguntarle sobre su salud, que ahora es buena, habiendo sanado del todo de la parálisis de todo el cuerpo de cintura abajo con agudos dolores que le ha aquejado por dos años, aunque dejándole enteramente despejada la cabeza; he seguido indagando lo que me ha parecido conveniente.

Me ha dicho que muchos le han instado para que publique su estudio, que abarca seis años, de 1605 á 1611, esto es, desde el fin del primero gobierno de Rivera hasta el principio del segundo: el Gobierno contribuye con diez mil pesos para la impresión y se imprimirá este año. Los ocho capítulos que ha mandado a casa son los últimos, y los anteriores están escritos y corregidos: todo está listo para la imprenta -Tiene además escrito lo que pertenece á la guerra defensiva en años posteriores; pero esto no se imprimirá.

Preguntándole yo qué sería lo que nosotros hubiéramos de observar ó notar, ha venido á decirme: He cercenado mucho de lo que tenía en mi escrito antiguo: he dulcificado cuanto me ha sido posible las cosas: y e procurado que aparezca que los graves errores y deslices del P. Valdivia no tuvieron apoyo ni aprobación en los Superiores de la Compañía, sino que al contrario, fuéron reprimidos: y desearía que cuanto hubiera que advertir en esto, me lo dijesen para enmendarlo: ya que en lo sustancial nada puedo cambiar.

Preguntado si las observaciones y demostraciones del P. Zoilo Villalón le habían hecho ver que se equivocase en puntos de importancia, me ha dicho: no me hicieron ningún efecto.

Añade que habiendo él dicho á un amigo que había dado á leer estos capítulos á los jesuítas, se lo ha desaprobado: y que teme no nos haga esto más daño que provecho, si se esparce la voz, porque parecerá que por depresivo que sea para nosotros lo que escribe, nosotros damos nuestra tácita aprobación. Yo le he dicho que si se juzga necesario, nosotros desharemos el error, como es claro, mostrando las cosas en que, según nuestro concepto, se equivoca el autor. Con esta ocasión he insinuado la idea de que cualquier autor, por interés de la verdad histórica y aun por propia conveniencia, está obligado a no afirmar sino lo que prueban los documentos, tratando como cierto lo que en ellos es cierto, y como sólo dudoso ó conjetural lo que en ellos no se contiene claramente: y he dicho que á 
esta obligación se añade obligación de justicia cuanto está de por medio la fmaa de una persona. En esto ha convenido el P. Crescente también. -Más adelante le he hecho notar que el número de documentos que hoy tenemos es incompleto y no permite resolver las cuestiones. Á esto me ha dicho que esto espera de nosotros, y que si presentamos algún documento positivo más, está pronto á reconocer lo que de él resulte.

Pensaba yo en retirarme, pues expresamente ha venido á concluir él lo que yo de antes tenía entendido, diciéndome: "no, Padre, en la sustancia estoy resuelto á no mudar nada, lo he estudiado muchísimos años: no digo más que lo que dicen los documentos, y estoy resuelto á no cambiar: es mi convicción”.

He juzgado conveniente sin embargo, apuntarle algunas ideas: $1^{\circ}$ La de que sostener la culpabilidad del P. Valdivia en pedir lo que el P. Crescente llama carta de ruego y encargo es hacer prevaricadores, malos católicos, malos sacerdotes, etc a todos los Obispos antiguos de América, y aun al Sr. Valdivieso. -Me lo ha concedido de algunos añadiendo: aunque fueran todos ¿qué? - En cuanto al Sr. Valdivieso, se ha mostrado afligido y ofendido: me ha referido un caso que sucedió con el P. Villalón por haber suscitado esta especie: y se ha puesto tan fuerte que ha sido preciso dejarlo. - Y diciendo yo por incidencia: por haber sido un año profeso de derecho canónico; me ha dicho: yo lo fui once años y tengo escrito el texto.

$2^{\circ}$ Pasando al hecho, le he hecho observar que no consta de la negociación del $\mathrm{P}$. Valdivia para ser Obispo ni del testimonio de la Junta, que dice parece y se podrá explicar de otro modo, ni de la carta del Padre, que es oscura: concede lo $2^{\circ}$ y niega lo $1^{\circ}$. Probándole yo que hubiera sido sacrilegio, se ha extrañado algo. $-Y$ extrañando yo a mi vez que siendo él quien primero ha hecho este cargo no hable de nuestros historiadores que dicen lo contrario, ha respondido que suprimió lo que sobre esto tenía escrito por no descreditarlos; pero no tiene inconveniente en poner en acta esto y cuantos reparos le queramos hacer.

Con esto me levanté y despedí con el afecto posible, y él con alguna frialdad.

Colegio de San Ignacio, Santiago de Chile, 7 de febrero de 1908.

Pablo Hernández, S.I. 
